\title{
ESTIMATION OF CANOPY HEIGHT AND BIOMASS OF MISCANTHUS SINENSIS IN SEMI-NATURAL GRASSLAND USING TIME-SERIES UAV DATA
}

\author{
Naoko Miura $^{1 *}$, Susumu Yamada ${ }^{2}$, Yuji Niwa ${ }^{1}$ \\ ${ }^{1}$ Graduate School of Agricultural and Life Sciences, the University of Tokyo - miura@uf.a.u-tokyo.ac.jp, uz28@uf.a.u-tokyo.ac.jp \\ ${ }^{2}$ Faculty of Agriculture, Tokyo University of Agriculture - sy206447@nodai.ac.jp
}

KEY WORDS: UAV, time-series, semi-natural grassland, grass height, biomass, SfM-MVS

\begin{abstract}
:
Grasslands are important ecosystems to provide various economic and ecological services. In Japan, grassland of Miscanthus sinensis, which is a tall, perennial grass species, has been one of the symbolic landscape and require efficient monitoring system for better management. In this study, canopy height and biomass of $M$. sinensis in semi-natural grassland are estimated using time-series UAV imagery and structure from motion (SfM) and multi-view stereo (MVS) technique. The effect of complex topography on estimation of the canopy height and biomass is analysed as well as monitoring growth of M. sinensis. The results showed that UAV derived maximum canopy height and biomass have significant correlation with vegetation survey data producing $\mathrm{R}^{2}$ value of 0.92 and 0.78 , respectively. The effect of topographic landforms was found to be smallest on top of the hill, followed by slope. Valley-like sunken place was affected worst. Analysis using time-series UAV data revealed that growth of $M$. sinensis is different between the landforms, and the best time to estimate its biomass was different between them. In order to accurately estimate canopy height and biomass of tall grass species such as $M$. sinensis, it is important to take plant growth stage into consideration as well as topographic landforms.
\end{abstract}

\section{INTRODUCTION}

Grasslands are important ecosystems to provide various economic and ecological services such as water conservation (e.g. Bilotta et al., 2010), carbon sequestration (e.g. O'Mara, 2012) and habitat for wildlife (e.g. Milligan et al., 2020; Port et al., 2019). In Japan, grassland of Miscanthus sinensis (Figure 1), which is a tall, perennial grass species and characterized by erect and tufted forms (Hayashi et al., 1981), has been one of the symbolic landscape and supplied food for livestock, compost for the crops, and materials for traditional roof. It is a semi-natural grassland and requires controlled burn to maintain the grassland, otherwise it succeeds to forests due to a temperate climate and abundant rainfall. It has been reported that the grassland of $M$. sinensis has been decreased, since local communities are increasingly shorthanded for controlled burn these days (Takahashi, 2019). Efficient monitoring system of the grassland would help for better grassland management.

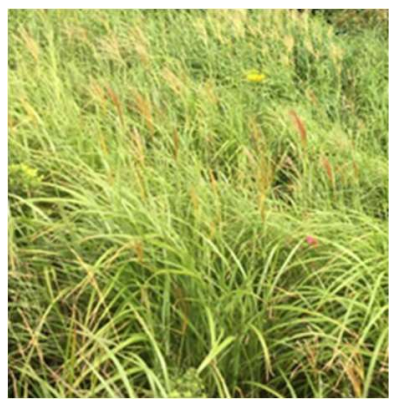

Figure 1. Miscanthus sinensis

The recent development of unmanned aerial vehicle (UAV) technology offers the potential to study and monitor grasslands, since it can acquire data more frequently with higher spatial resolution (in the order of centimetres) in cost-effective manner, compared to the conventional airborne data acquisition by airplane. It is a non-destructive method to derive plant parameters in large area, compared to traditional destructive field measurement techniques (Catchpole and Wheeler, 1992). Using UAV LiDAR which is an active sensor, Miura et al. (2019; 2018) estimated herbaceous vegetation height and its vertical structure on riverdike. With a combination of structure from motion (SfM) and multi-view stereo (MVS) technique, passively acquired UAV imagery can also generate 3D information. Studies have shown that sward height derived from UAV imagery is promising parameter to estimate grassland biomass (e.g. Bendig et al., 2014; Forsmoo et al., 2018; Grüner et al., 2019; Lussem et al., 2019; Zhang et al., 2018).

In this study, canopy height and biomass of $M$. sinensis in seminatural grassland are estimated using time-series UAV imagery. The challenge of this study is that UAV data are acquired over the natural complex topography. Most of existing grassland studies using UAV aims to predict crop yield, therefore, study sites are relatively flat. To our knowledge concerning grassland studies using UAV data, the effect of complex topography on estimation of the canopy height and biomass is unknown. We use time-series UAV data, which covers whole growing season of $M$. sinensis. This is because tall grass species tend to hang their canopy as they grow excessively, it may affect the estimation of canopy height and biomass. Therefore, growth of M. sinensis is monitored and analysed in conjunction with the topography.

\section{METHODS}

\subsection{Study area}

The Study area is approximately 22 ha and locates in Nebara district, Asagiri Highlands at the western foot of Mt. Fuji in

* Corresponding author 
Shizuoka Prefecture, Japan $\left(138^{\circ} 35^{\prime} 47.133^{\prime \prime} E 3^{\circ} 25^{\prime} 32.151^{\prime \prime N}\right.$, Figure 2). The elevation ranges from $926 \mathrm{~m}$ to $977 \mathrm{~m}$ above sea level. Mean annual precipitation and temperature are $2249 \mathrm{~mm}$ and $10.6{ }^{\circ} \mathrm{C}$, at the nearby Shiraito Meteorological Station and Kawaguchi-ko Meteorological Station respectively. Grassland which mainly consists of $M$. sinensis spreads over a plateau of lava where complex topography was formed. Nebara district is a famous field of $M$. sinensis, which is used for repairing roof of cultural assets, and registered in 2012 by Agency for Cultural Affairs, Government of Japan as an important area to conserve materials used for cultural properties. The grassland is burnt annually in April to produce good quality M. sinensis. After the burn, M. sinensis grows until it attains maturity in September. Then, it withers in the next couple of months and is finally harvested during winter before the annual control burn is conducted in the next April.

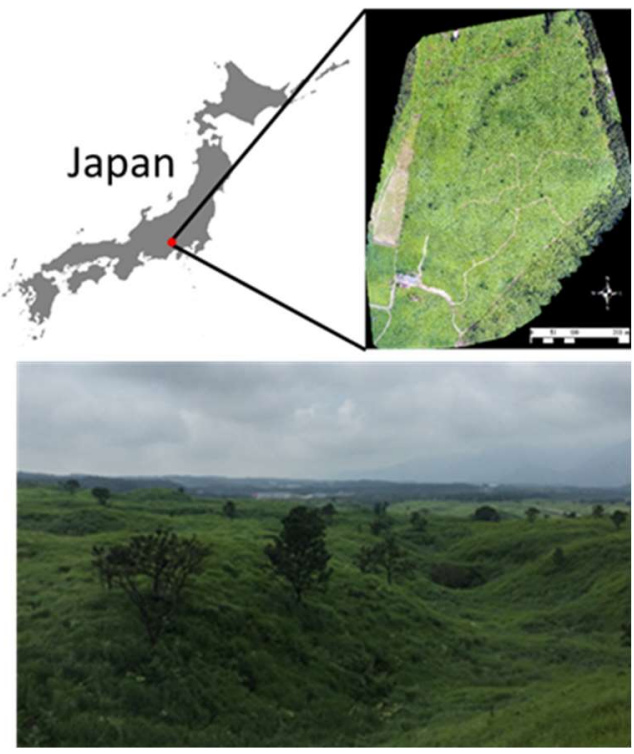

Figure 2. Study area

\subsection{UAV data}

UAV data were acquired monthly from April to August in 2019 using DJI Phantom 4 advanced, which is a multirotor drone with a 1 inch CMOS sensor camera. Flight altitude was set as $75 \mathrm{~m}$ from the ground, which resulted in image data with a Ground sampling distance (GSD) of between 2.31 and $2.41 \mathrm{~cm}$. Mission Planner (ver. 20170910) software was used to prepare the flight. RGB images were captured with 2 seconds shutter interval, and $80 \% / 80 \%$ side/forward overlap. Litchi application was used for autopilot of the drone. Two flight missions were repeated with exactly the same camera parameters to cover the study area each month. Ground control points (GCPs) were set up at 41 places (Figure 3) and GNSS survey was conducted using Leica GS18T in terms of their $\mathrm{x}, \mathrm{y}, \mathrm{z}$ position. We distributed them evenly in the study area, considering the elevation difference (Figure 3). Additionally, seven places were GNSS surveyed as validation points to examine $\mathrm{z}$ values of UAV data products.

The captured images in each month were processed to produce Digital Surface Model (DSM), orthomosaic image and point cloud using SfM + MVS software, Pix4D.

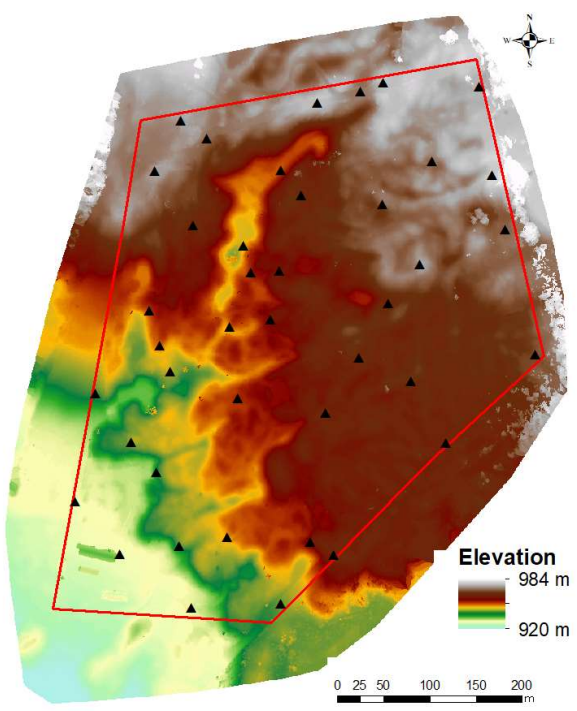

Figure 3. GCPs (black triangle) in the study area (red polygon)

\subsection{Vegetation survey}

Vegetation survey was conducted on 3 September 2019, which is 12 days after the images were acquired in August. This is about the same time when $M$. sinensis attains maturity and maximum biomass. Vegetation condition had not changed much since the UAV data acquisition. A circular plot of $62.5 \mathrm{~cm}$ diameter $(0.31$ $\mathrm{m}^{2}$ ) was set up on each of the three topographic landforms; top of the hill, slope (43.9-70\%) and valley-like sunken place of the plateau of lava, where M. sinensis dominates (Figure 4). This is because the growth of $M$. sinensis is assumed to be different between the landforms, and also the accuracy of canopy height and volume estimation using UAV data might be affected by the difference of these landforms. Totally 20 plots, which include 6 plots for top of the hill and 7 plots for each of slope and sunken place, were set up (Figure 5). The center of the plot was GNSS surveyed using Propeller Aeropoints as well as recording three maximum canopy height of $M$. sinensis using a holding ruler and names of other vegetation species in the plot. In order to measure their biomass, plants in the plots were mown, dried for 48 hours at $80{ }^{\circ} \mathrm{C}$ and weighted later in the laboratory.
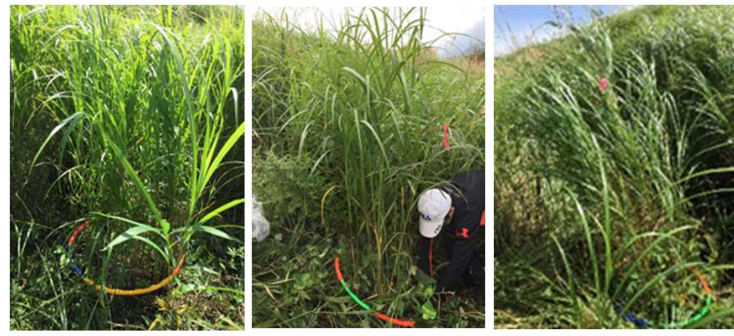

Figure 4. A circular plot of $62.5 \mathrm{~cm}$ diameter for vegetation survey on top of the hill (left), slope (center) and sunken place (right) 


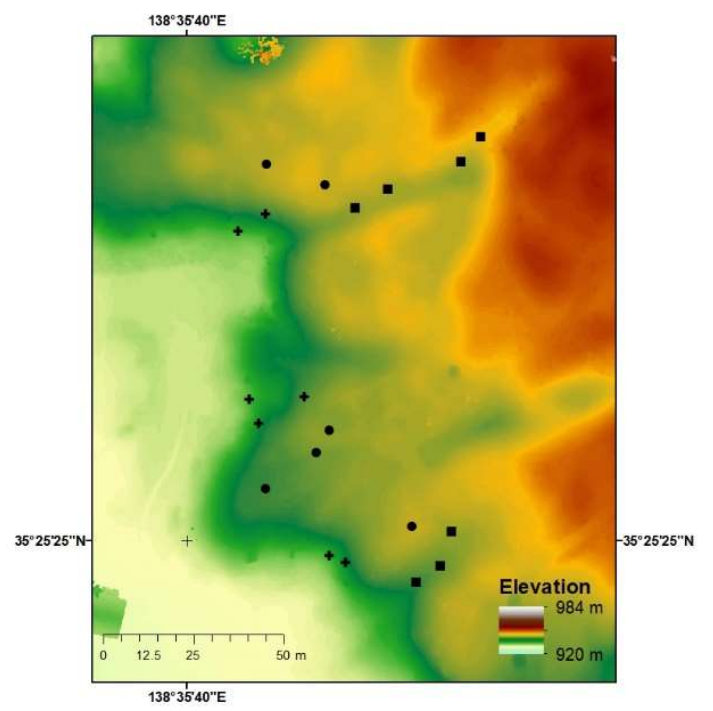

Figure 5. Location of the vegetation plots on the top of the hill (circle), slope (cross) and sunken place (rectangle).

\subsection{Canopy height and biomass of $M$. sinensis}

Canopy height and biomass of $M$. sinensis is calculated using DSM data generated by Pix4D. The DSM made from images acquired in April is defined as Digital Terrain Model (DTM), since there was no vegetation on the ground at the time of data acquisition due to annual burning in the area. Canopy height of M. sinensis in May, June, July and August was calculated by subtracting DTM from DSM of each month respectively. This creates Canopy Height Model (CHM) of each month. Since pixel size of the DTM and DSMs is between 2.31 and $2.41 \mathrm{~cm}$, there are 525 to 571 pixels with a canopy height value in a vegetation plot. For validation of canopy height, maximum height in each plot, which is derived from the CHMs, is compared to mean value of the three maximum vegetation height in each plot recorded in the vegetation survey.

Biomass of $M$. sinensis is calculated as a volume using the pixel size and canopy height information in each plot. The volume of each plot in each month from May to August, $V$ is expressed:

$$
V=\sum_{i=1}^{n} a^{2} h_{i}
$$

where $\quad a=$ pixel size of each CHM from May to August

$h=$ canopy height value of each pixel in each plot

$\mathrm{n}=$ the number of pixels in each plot

These values are then compared to the biomass measured in the vegetation survey.

\section{RESULTS}

\subsection{Z values of DTM and DSMs}

RMSE in $\mathrm{z}$ values of DTM and DSMs in each month against seven validation points were $6.7 \mathrm{~cm}$ (DTM), $5.9 \mathrm{~cm}$ (May), 5.7 $\mathrm{cm}$ (June), $5.5 \mathrm{~cm}$ (July) and $5.0 \mathrm{~cm}$ (August), respectively. Note that DSMs of July and August were validated using only six validation points, since the rock, which we used as a validation point, was moved sometime after data acquisition in June.

The $\mathrm{z}$ values of DTM were further validated using 20 vegetation plot center points, which results in RMSE value of $4.7 \mathrm{~cm}$. RMSE value in each of the three topographic landforms was $2.7 \mathrm{~cm}$ (top of the hill), $5.2 \mathrm{~cm}$ (slope) and $6.1 \mathrm{~cm}$ (sunken place), respectively.

\subsection{Canopy height of $M$. sinensis}

3.2.1 Maximum height: Table 1 shows the maximum height of M. sinensis in each plot in each month from May to August derived from UAV data and the mean maximum height recorded in vegetation survey in September. In terms of the three topographic landforms, the maximum height was highest in sunken place, followed by slope and top of the hill.

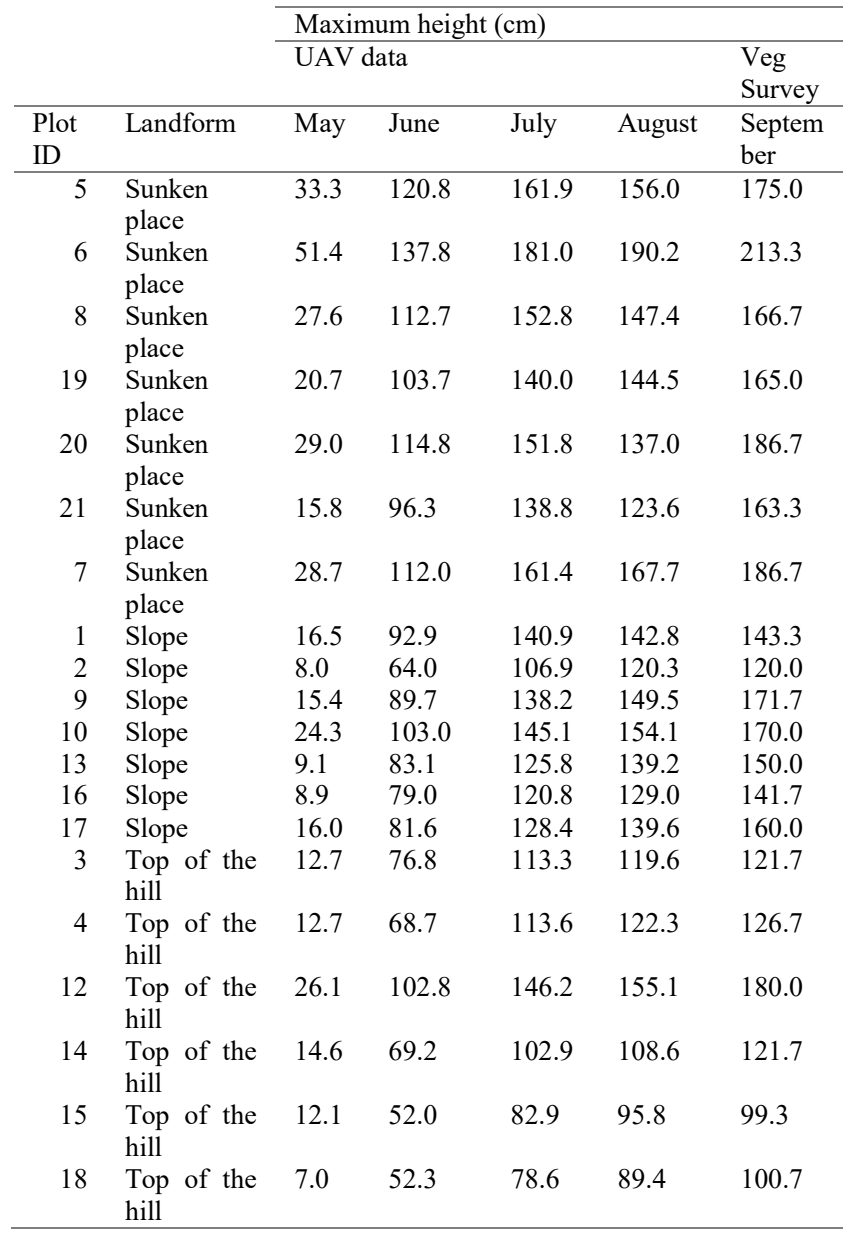

Table 1. Maximum height of M. sinensis in each plot derived from UAV data and vegetation survey

3.2.2 Comparison of maximum height between UAV data and vegetation survey: All the maximum height derived from UAV data displayed significant correlation with maximum height derived from vegetation survey with $\mathrm{R}^{2}$ value of 0.69 (May, Figure 6a), 0.90 (June, Figure 6b), 0.92 (July, Figure 6c) and 0.85 (August, Figure 6d), respectively $(p<0.01$ ). 


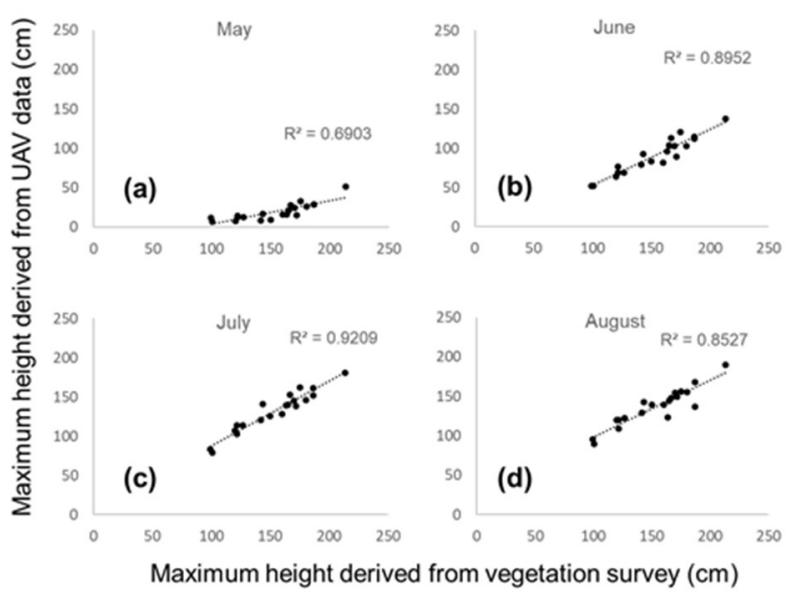

Figure 6. Comparison of maximum height of $M$. sinensis between UAV data: May (a), June (b), July (c) and August (d), and vegetation survey in September

3.2.3 Comparison of error in maximum height estimation between the three landforms: Table 2 exhibits RMSE values of maximum height derived from UAV data against maximum height derived from vegetation survey in different landforms; all, sunken place, slope and top of the hill. Between the three landforms, error in estimation of the maximum height was the smallest on top of the hill, followed by slope. The error was worst in sunken place except June data.

\begin{tabular}{lccrr} 
& \multicolumn{2}{l}{ RMSE $(\mathrm{cm})$} & & \\
\cline { 2 - 5 } Landform & May & June & July & August \\
\hline All & 139.0 & 65.1 & 24.0 & 21.1 \\
& & & & \\
Sunken place & 162.3 & 71.4 & 27.4 & 31.9 \\
Slope & 148.6 & 72.4 & 25.6 & 15.5 \\
Top of the hill & 123.6 & 61.1 & 22.3 & 13.8 \\
\hline
\end{tabular}

Table 2. RMSE values of maximum height derived from UAV data against maximum height derived from vegetation survey in different landforms; all, sunken place, slope and top of the hill

3.2.4 Comparison of mean growth length between the three landforms: Mean growth length of $M$. sinensis in each plot was calculated monthly in the three landforms; sunken place, slope and top of the hill (Figure 7). M. sinensis grew most in a month from May to June $(40.3-93.7 \mathrm{~cm})$, followed by a month from June to July $(24.5-52.3 \mathrm{~cm})$. It did not grow much in a month from April to May $(3.8-40.5 \mathrm{~cm})$, and from July to August $(-8.9-11.6 \mathrm{~cm})$. This tendency was consistent between the landforms. Comparison between the landforms was conducted statistically using ANOVA and Tukey-Kramer. Mean growth length in sunken place was significantly different from that in other landforms most of the time except a month from June to July. Furthermore, it showed negative growth in a month from July to August.

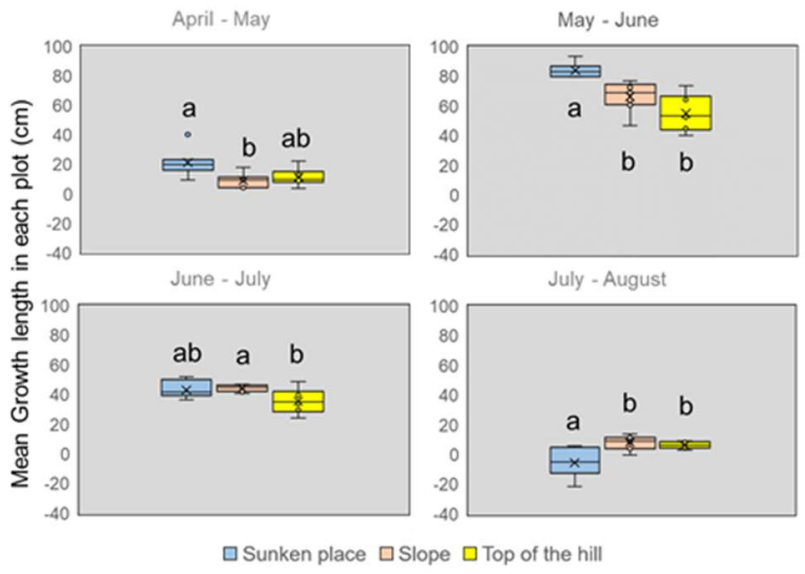

Figure 7. Monthly mean growth length of $M$. sinensis in each plot in the three landforms; sunken place, slope and top of the hill. The different alphabet shows significant difference between the landforms $(p<0.05)$

\subsection{Biomass of $M$. sinensis}

3.3.1 Comparison between UAV data and vegetation survey: Figure 8 shows comparison between volume of $M$. sinensis derived from UAV data and biomass derived from vegetation survey. The volume derived from UAV data was significantly correlated with biomass derived from vegetation survey with $\mathrm{R}^{2}$ value of 0.63 (May, Figure $8 \mathrm{a}$ ), 0.78 (June, Figure 8b), 0.76 (July, Figure 8c) and 0.55 (August, Figure 8d), respectively $(p<0.01)$. Biomass of $M$. sinensis was best estimated using June data (Figure $8 b$ ).

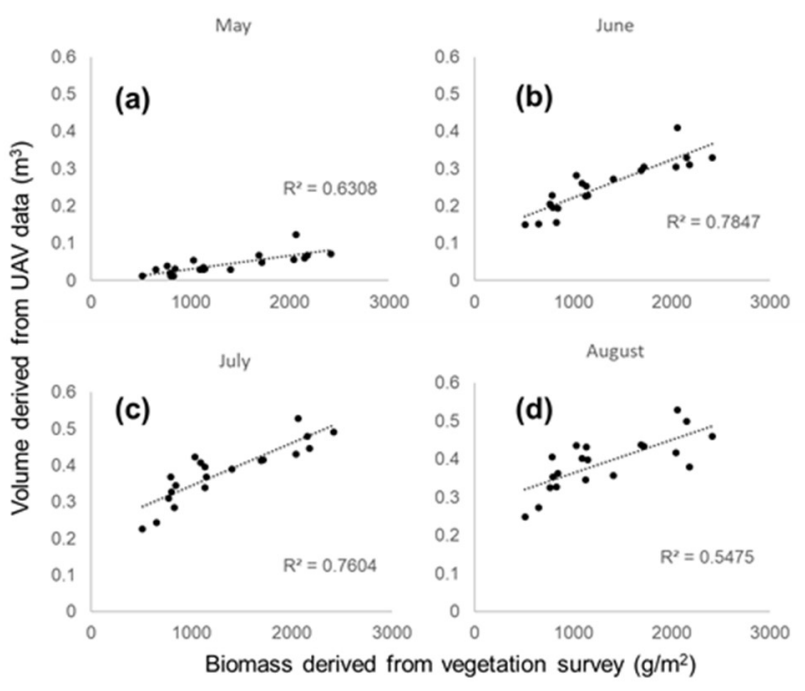

Figure 8. Comparison between volume of $M$. sinensis derived from UAV data: May (a), June (b), July (c) and August (d), and biomass derived from vegetation survey in September 


\subsubsection{Comparison between the three landforms:} Comparison between volume of $M$. sinensis derived from UAV data and biomass derived from vegetation survey was then conducted separately in each of the three landforms; sunken place (Figure 9), slope (Figure 10) and top of the hill (Figure 11). In sunken place, the correlation between them was not significant, however, biomass was best estimated using July data (Figure 9c) with $\mathrm{R}^{2}$ value of 0.54 . On the slope, the correlation was not significant, however, May and July data estimated biomass well with $\mathrm{R}^{2}$ value of 0.47 (Figure 10a) and 0.45 (Figure 10c), respectively. On top of the hill, the correlation was all significant with $\mathrm{R}^{2}$ value of 0.79 (May, $p<0.05$, Figure 11a), 0.94 (June, $p$ $<0.01$, Figure 11b), 0.83 (July, $p<0.05$, Figure 11c) and 0.86 (August, $p<0.01$, Figure 11d). Biomass was best estimated using June data (Figure 11b).

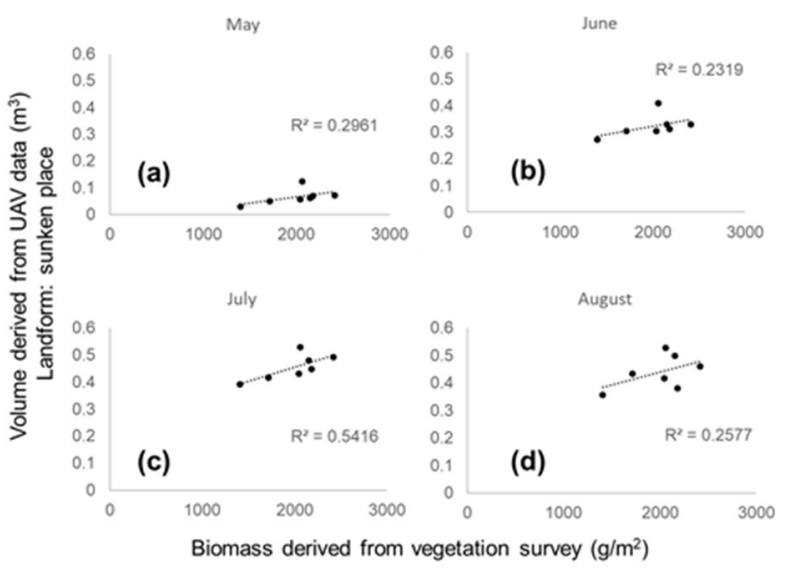

Figure 9. Comparison between volume of $M$. sinensis derived from UAV data: May (a), June (b), July (c) and August (d), and biomass derived from vegetation survey in September, in the landform of sunken place

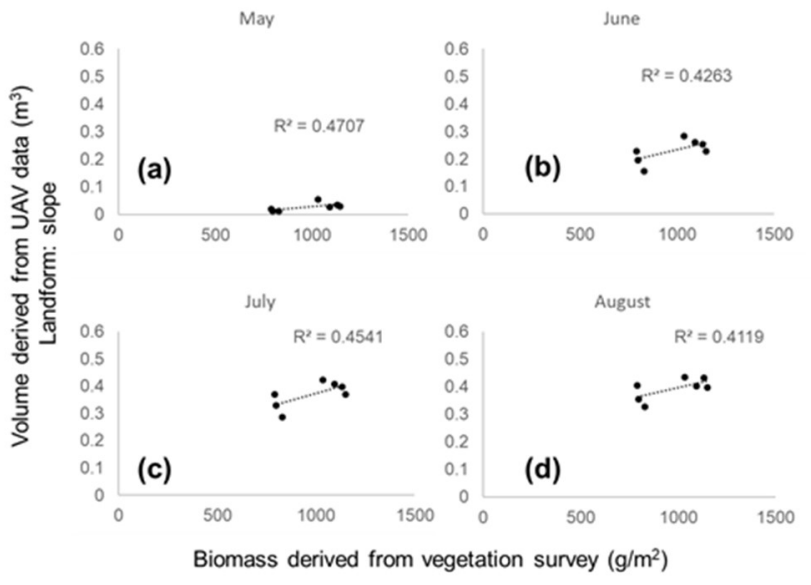

Figure 10. Comparison between volume of $M$. sinensis derived from UAV data: May (a), June (b), July (c) and August (d), and biomass derived from vegetation survey in September, in the landform of slope

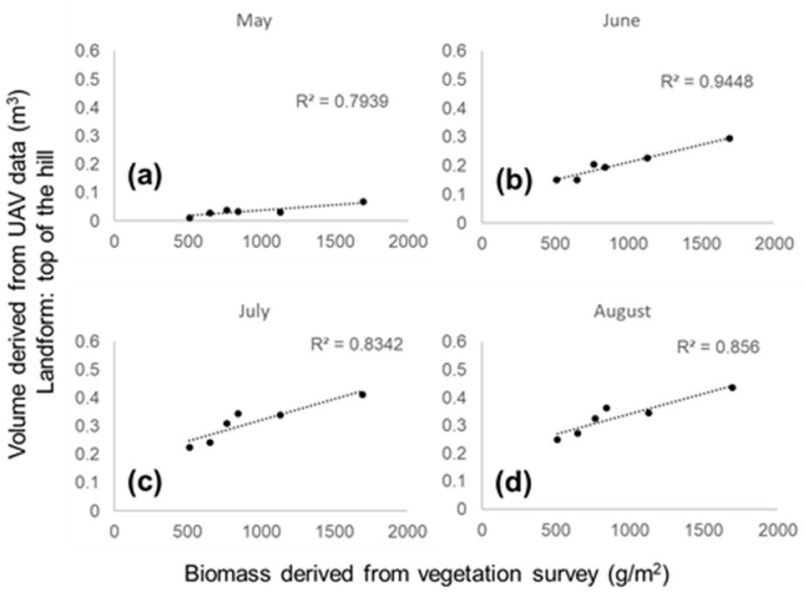

Figure 11. Comparison between volume of $M$. sinensis derived from UAV data: May (a), June (b), July (c) and August (d), and biomass derived from vegetation survey in September, in the landform of top of the hill

\section{DISCUSSION}

The accuracy of $z$ values of DTM and DSMs was considered to be reasonable with RMSE of 5.0-6.7 $\mathrm{cm}$ at GSD of 2.31-2.41 cm, compared to other grassland studies. For example, Nasi et al. (2018), Viljanen et al. (2018) and Borra-Serrano et al. (2019) presented RMSE of $6.9 \mathrm{~cm}$ at GSD of $1 \mathrm{~cm}$, RMSE of 1.0-4.8 $\mathrm{cm}$ at GSD of 0.39-0.64 cm, and RMSE of $<2 \mathrm{~cm}$ at GSD of $0.6 \mathrm{~cm}$, respectively. The effect of topographic landforms on the accuracy of $z$ values of the DTM was apparent, since there was no effect of vegetation in this dataset. The error was small (RMSE of $2.7 \mathrm{~cm}$ ) on the top of the hill where the ground is relatively flat with very gentle slope. On the other hand, the accuracy of $z$ values becomes worse on slope and sunken place where topography is more complex.

The comparison of maximum canopy height between UAV data and vegetation survey suggests that the height can be well estimated using a regression model. The best $\mathrm{R}^{2}$ value of 0.92 (Figure 6b) was better than similar studies such as $\mathrm{R}^{2}$ value of 0.56 and 0.7 in Grüner et al. (2019) and $R^{2}$ value of 0.61 and 0.93 in Forsmoo et al. (2018). However, the estimation of absolute height was found to be difficult using UAV data alone (Table 2). Considering the error of $\mathrm{z}$ values in DTM and DSM was less than $6.7 \mathrm{~cm}$, the error of $21.1 \mathrm{~cm}$ (Table 2, August) was somewhat large. This error could be originated from both UAV data and vegetation survey. Since tall grass species easily leans and sways with wind, it is very difficult to measure maximum canopy height in the field as well as capturing by UAV.

The effect of topographic landforms on estimating maximum canopy height was again clear, and had the same trend with the result in validation of $z$ values of DTM; the error was smallest on top of the hill, followed by slope and sunken place (Table 2). This trend was almost consistent throughout the study period.

It was noted that in sunken place, the error in July data (RMSE $=$ $27.4 \mathrm{~cm})$ was smaller than that in August data $(\mathrm{RMSE}=31.9 \mathrm{~cm})$ (Table 2). Since the vegetation survey was conducted in September, the error should be smaller in August. The analysis of monthly mean growth length of M. sinensis implies that it grew greatly in sunken place from May to June (Figure 7), therefore, it started hanging its canopy down in August as it grew, which 
results in the negative growth in a month from July to August (Figure 7). This can be supported by the profile of point cloud of each month from May to August (Figure 12). In sunken place, point cloud of August was observed under the point cloud of July at some area (Figure 12c). In valley-like sunken place, rain water often flows through at the bottom, which creates micro gully. It is also likely that over-grown $M$. sinensis leaned in the space of gully in August. Since UAV images can capture only surface, consequently canopy height derived from UAV data was decreased. This also explains why the maximum canopy height was best estimated by July data than by August data in terms of $\mathrm{R}^{2}$ value (Figure $6 \mathrm{c}$ ).

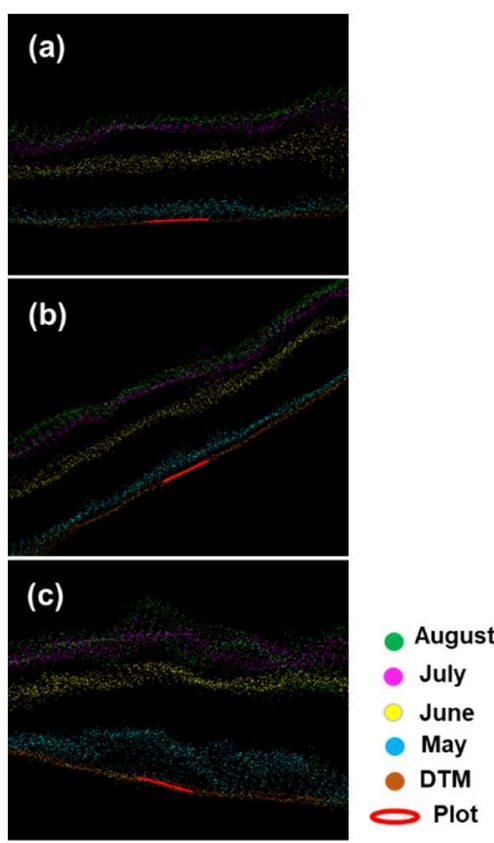

Figure 12. Point cloud of each month from May to August on top of the hill (a), slope (b) and sunken place (c)

The proposed method to estimate biomass of $M$. sinensis worked well. June data has the best potential to predict biomass of $M$. sinensis in this area (Figure 8b). By topographic landforms, July data estimated biomass best for sunken place (Figure 9c), while June data did for top of the hill (Figure 11b). As for slope, $\mathrm{R}^{2}$ value was slightly better in May data (Figure 10a) than July data (Figure 10c), however, vegetation condition in May was thought to be too early to predict biomass, and July data would estimate it better. It was considered that growth stage of $M$. sinensis, which is different between topographic landforms, is a key to estimate biomass.

It was not August data but June or July data to estimate biomass of $M$. sinensis best during its growing season. In other words, biomass of $M$. sinensis can be estimated before it reaches full grown stage. This could be advantage in vegetation management. Managers can know the biomass of the grassland long before $M$. sinensis is harvested for traditional roof materials in winter or controlled burn is planned.

In this study, two flight missions were necessary to cover the whole study area with current specification of UAV data acquisition. In order to cover a larger region efficiently, flight altitude could be set higher than $75 \mathrm{~m}$, however, that would result in larger GSD which might or might not work for estimating canopy height and biomass of grass species such as M. sinensis.
This needs further investigation. Full-frame digital cameras could be used to capture similar high-quality images to this study at higher altitude, although a larger $\mathrm{UAV}$ is required to mount the camera.

In conclusion, canopy height and biomass of $M$. sinensis in seminatural grassland were well estimated using time-series UAV imagery. It was found that the difference in topographic landforms affects accuracy of $\mathrm{z}$ values of DTM and DSM, which were generated by SfM-MVS technique. Analysis using timeseries UAV data revealed that growth of $M$. sinensis is different between the landforms, and the best time to estimate its biomass was different between them. In order to accurately estimate canopy height and biomass of tall grass species such as $M$. sinensis, it is important to take plant growth stage into consideration as well as topographic landforms.

\section{ACKNOWLEDGEMENTS}

This research was supported by Ichimura Foundation for Technology. We thank Kiyohito Yoshikawa for his support in the field. We also acknowledge Mitsuru Negishi for his assistance in vegetation survey.

\section{REFERENCES}

Bendig, J., Bolten, A., Bennertz, S., Broscheit, J., Eichfuss, S., Bareth, G., 2014. Estimating Biomass of Barley Using Crop Surface Models (CSMs) Derived from UAV-Based RGB Imaging. Remote Sensing 6, pp. 10395-10412.

Bilotta, G.S., Krueger, T., Brazier, R.E., Butler, P., Freer, J., Hawkins, J.M.B., Haygarth, P.M., Macleod, C.J.A., Quinton, J.N., 2010. Assessing catchment-scale erosion and yields of suspended solids from improved temperate grassland. Journal of Environmental Monitoring 12, pp. 731-739.

Borra-Serrano, I., De Swaef, T., Muylle, H., Nuyttens, D., Vangeyte, J., Mertens, K., Saeys, W., Somers, B., Roldan-Ruiz, I., Lootens, P., 2019. Canopy height measurements and nondestructive biomass estimation of Lolium perenne swards using UAV imagery. Grass and Forage Science 74, pp. 356-369.

Catchpole, W.R., Wheeler, C.J., 1992. Estimating plant biomass: A review of techniques. Australian Journal of Ecology 17, pp. 121-131.

Forsmoo, J., Anderson, K., Macleod, C.J.A., Wilkinson, M.E., Brazier, R., 2018. Drone based structure from motion photogrammetry captures grassland sward height variability. Journal of Applied Ecology 55, pp. 2587-2599.

Grüner, E., Astor, T., Wachendorf, M., 2019. Biomass Prediction of Heterogeneous Temperate Grasslands Using an SfM Approach Based on UAV Imaging. Agronomy 9, p. 54.

Hayashi, I., Hishinuma, Y., Yamasawa, T., 1981. Structure and functioning of Miscanthus sinensis grassland in Sugadaira, Central Japan. Vegetatio 48, pp. 17-25.

Lussem, U., Bolten, A., Menne, J., Gnyp, M.L., Schellberg, J., Bareth, G., 2019. Estimating biomass in temperate grassland with high resolution canopy surface models from UAV-based RGB images and vegetation indices. Journal of Applied Remote Sensing 13. 
Milligan, M.C., Berkeley, L.I., McNew, L.B., 2020. Effects of Rangeland Management on the Nesting Ecology of Sharp-Tailed Grouse. Rangeland Ecology \& Management 73, pp. 128-137.

Miura, N., Koyanagi, T.F., Yokota, S., Yamada, S., 2019. Can UAV LiDAR derive vertical structure of herbaceous vegetation on riverdike? ISPRS Ann. Photogramm. Remote Sens. Spatial Inf. Sci. IV-2/W5, pp. 127-132.

Miura, N., Yokota, S., Koyanagi, T.F., Yamada, S., 2018. Herbaceous vegetation height map on riverdike derived from UAV LiDAR data, 2018 IEEE International Geoscience and Remote Sensing Symposium (IGARSS).

Nasi, R., Viljanen, N., Kaivosoja, J., Alhonoja, K., Hakala, T., Markelin, L., Honkavaara, E., 2018. Estimating Biomass and Nitrogen Amount of Barley and Grass Using UAV and Aircraft Based Spectral and Photogrammetric 3D Features. Remote Sensing 10.

O'Mara, F.P., 2012. The role of grasslands in food security and climate change. Annals of Botany 110, pp. 1263-1270.

Port, J., Crawford, C., Campbell, B., Larson, R., Lin-Celeste, P., Walton, M., 2019. Use of Four Grassland Types by Small Mammal Species in Southern Minnesota. Ecological Restoration 37, pp. 256-262.

Takahashi, Y., 2019. Semi-natural grassland ecosystem as managed nature of Japan. Reintroduction 7, pp. 1-9.

Viljanen, N., Honkavaara, E., Nasi, R., Hakala, T., Niemelainen, O., Kaivosoja, J., 2018. A Novel Machine Learning Method for Estimating Biomass of Grass Swards Using a Photogrammetric Canopy Height Model, Images and Vegetation Indices Captured by a Drone. Agriculture-Basel 8.

Zhang, H., Sun, Y., Chang, L., Qin, Y., Chen, J., Qin, Y., Du, J., Yi, S., Wang, Y., 2018. Estimation of Grassland Canopy Height and Aboveground Biomass at the Quadrat Scale Using Unmanned Aerial Vehicle. Remote Sensing 10, p. 851. 